\title{
Epoxy Resin with Amphiphilic Ionic Liquid as Hydrophobic Organic Coating for Steel
}

\author{
Ayman M. Atta ${ }^{1,}$, Eid M.S. Azzam ${ }^{2, *}$, Khalaf M. Alenezi ${ }^{2}$, Hani El Moll ${ }^{2}$ and A. Haque ${ }^{2}$ \\ ${ }^{1}$ Chemistry department, college of science, king Saud university, Riyadh11545, Saudi Arabia. \\ ${ }^{2}$ University of Hail, college of science, department of chemistry, 81451 Hail, Saudi Arabia. \\ *E-mail: aatta@ksu.edu.sa (A.M.A.) and eazzamep@yahoo.com (E.M.S.A).
}

doi: $10.20964 / 2021.06 .45$

Received: 1 March 2021 / Accepted: 7 April 2021 / Published: 30 April 2021

The ionic liquids (ILs) have been proposed as curing modifiers to obtain superior epoxy coatings. In the present work, the imidazolium and pyridinium cations combined in amphiphilic hardener based on polyamines to apply as curing for epoxy resin and to obtain organic coatings on the steel surface. In this respect, the primary amine groups of triethylenetetramine, pentaethylenehexamine or aminopyridinum tetradecylbromide was condensed with p-hydroxybenzaldehyde and glyoxal to obtain new ILs. The phenol group of the produced ILs were etherified with tetraethylene glycol to obtain amiphiphilic ILs. The chemical structure, thermal stability, and thermal characteristics as new ILs were characterized. The curing exotherms of the epoxy resins with the liquid ILs were evaluated from diffraction scanning calorimetric (DSC) and thermostated curing system to determine the maximum curing exothermic temperatures and times. The cured epoxy coatings were applied on the steel surfaces to investigate their adhesion strengths, morphologies and seawater salt spray resistance. The data confirm that the cured epoxy resin in the presence of ILs hardeners show higher adhesion strengths and salt spray exposure time more than $15 \mathrm{MPa}$ and $2000 \mathrm{~h}$, respectively.

Keywords: Epoxy; Ionic liquids; Imidazolium and pyridinium cations; Coatings; Adhesion.

\section{$\underline{\text { FULL TEXT }}$}

(C) 2021 The Authors. Published by ESG (www.electrochemsci.org). This article is an open access article distributed under the terms and conditions of the Creative Commons Attribution license (http://creativecommons.org/licenses/by/4.0/). 